\title{
Development of a meteorological forecast for snow accumulation on transmission lines
}

\author{
Tatsuhito Ito, Masaru Yamaoka, Hisayuki Ohura, \\ Hokkaido Electric Power Co., Inc., Sapporo, Japan \\ TAKASHI TANIGUCHI, \\ Hokkaido Head Office of Japan Weather Association, Sapporo, Japan \\ GOROW WAKAHAMA \\ Institute of Low Temperature Science, Hokkaido University, Sapporo 060, Japan
}

\begin{abstract}
In Hokkaido we have often experienced hazardous accidents, such as tower collapses and conductor breakage, caused by wet-snow accretion on transmission lines, and over many years have developed countermeasures for wetsnow accretion. Recently we have been developing a system to forecast areas where snow accretion may occur. We used the southern part of Hokkaido, divided into $5 \mathrm{~km} \times 5 \mathrm{~km}$ meshes, as a forecast area; our predictions were hourly, 3-24 hours in advance. A method of predicting meteorological data which forms an important part of the system predicts three elements which influence wet-snow accretion: air temperature, precipitation, and wind direction and speed. We used an interpolation for predicting temperature and precipitation and a one-level, mesoscale model for diagnosing surface winds for wind direction and speed. By applying the method to many examples of wet-snow accretion, we checked the prediction of weather elements.
\end{abstract}

\section{INTRODUCTION}

The Hokkaido Electric Power Co., Inc. is responsible for clectric power supply in Hokkaido. The winter climate in Hokkaido is very severe and in the past depressions have sometimes brought wet snow accretion, galloping on transmission lines, or tower collapse due to breakage of wires. To cope with these problems, we began studying countermeasures for snow accretion on transmission lines and developed snow-resistant rings and anti-torsional dampers.

We also utilize meteorological information offered by the Japan Meteorological Agency (JMA). For the purpose of maintening electric power equipment and electric power systems, we have been studying meteorological prediction and developing a system to forecast areas where snow accretion may occur.

Snow accumulates on transmission lines when meteorological elements - air temperature, precipitation and wind - combine within a certain range. Therefore it is necessary to predict these meteorological elements in order to forecast snow accretion.

This paper mainly describes the method of predicting meteorological data which forms part of the snowaccretion forecasting system.
J.M.A.

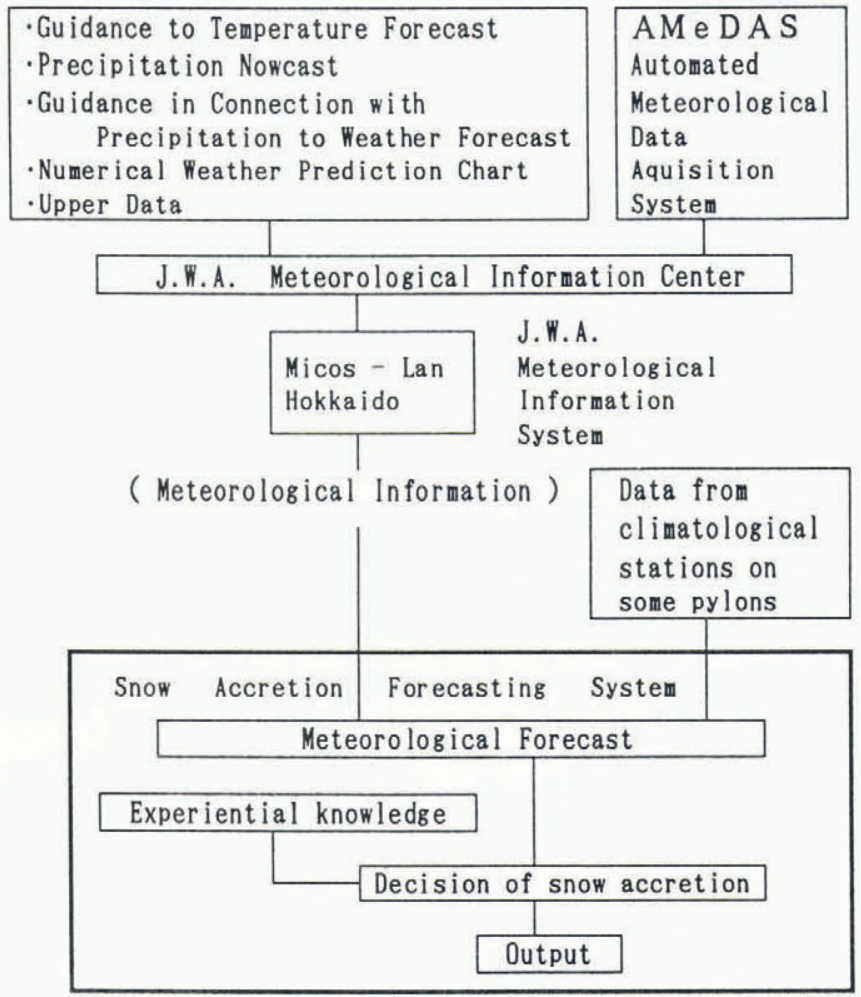

Fig. 1. Configuration of snow accretion forecasting. 


\section{OUTLINE OF SNOW-ACGRETION FORECAST- ING SYSTEM}

In winter, when a growing depression approaches Hokkaido and the weather conditions develop into a certain range, wet-snow accretion occurs on transmission lines. It would be very useful for operators of electric power systems and staff of maintenance offices to be able to forecast areas where snow accretion may occur in time to take appropriate countermeasures.

Figure 1 shows the configuration of the snow-accretion forecasting system. The kinds of data used are: (1) predicted values based on meteorological information (air temperature, precipitation, wind direction and speed, etc.) which are available from the JMA and the JWA (Japan Weather Association); (2) the data from climatological station on some pylons; and (3) experiential knowledge of snow accretion in the past.

\section{METHOD OF PREDICTING METEOROLOGICAL ELEMENTS}

Meteorological factors related to snow accretion on transmission lines are air temperature, wind direction and speed, and precipitation (primarily wet snow). We used meteorological information received from the JMA and the JWA to produce the "nowcast" (several hours ahead) and the short-range forecast (a day ahead). The area that we used in forecasting was the southern part of Hokkaido where there is sometimes damage due to wetsnow accretion on transmission lines. The area was divided into $5 \mathrm{~km} \times 5 \mathrm{~km}$ meshes.

\section{Technique of predicting temperature}

The flow-chart for predicting temperature is shown in Figure 2. First, we transformed the minimum and

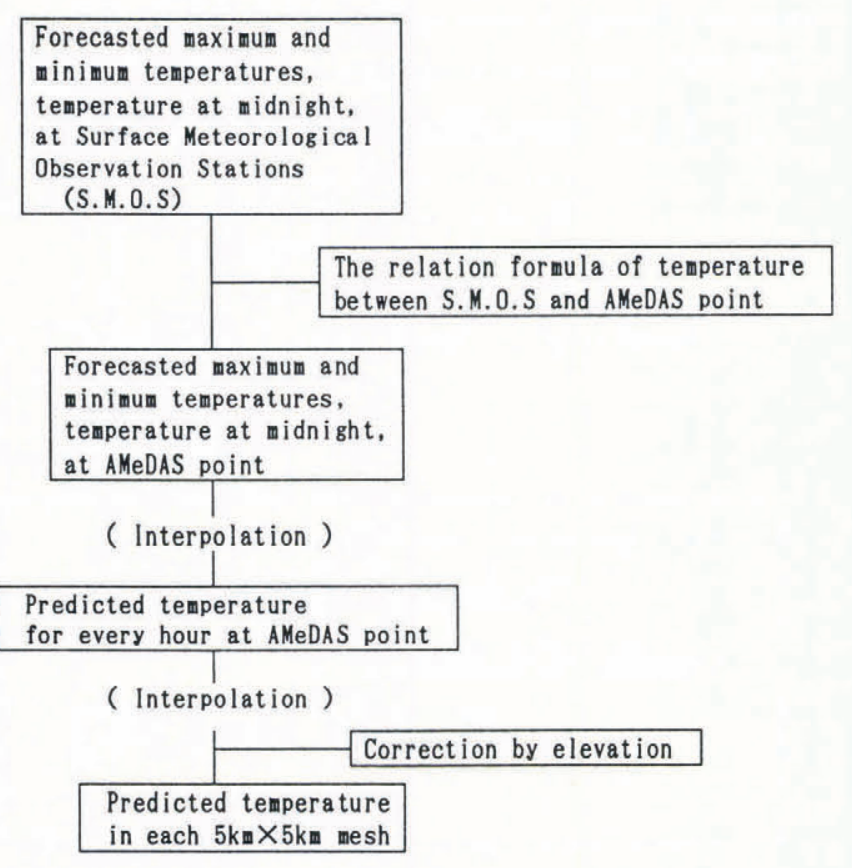

Fig. 2. Flow chart for predicting temperature.

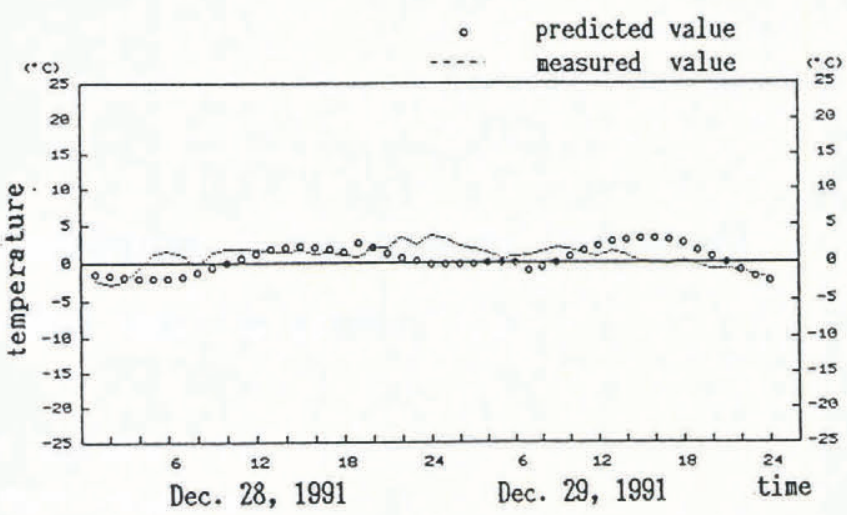

Fig. 3. Interpolating at an AMeDAS point (Hakodate). $\circ$, predicted value; - - -, measured value.

maximum temperatures in a day and the temperature at midnight, measured at surface meteorological observation stations, to the temperature at AMeDAS point. (AMeDAS is the Automated Meteorological Data Acquisition System developed by the JMA.) At this stage, we used a relational formula obtained by statistical analysis in advance. Next, through a Spline function, we calculated the temperature for every hour using the above temperatures at each AMeDAS point and the current temperature (Fig. 3).

We also calculated the temperature lapse rate of elevation for every hour. This rate was obtained from the relationship between temperature and elevation at AMeDAS points, and from the relationship between upper temperature and altitude at $850 \mathrm{mb}$, as shown in Figure 4.

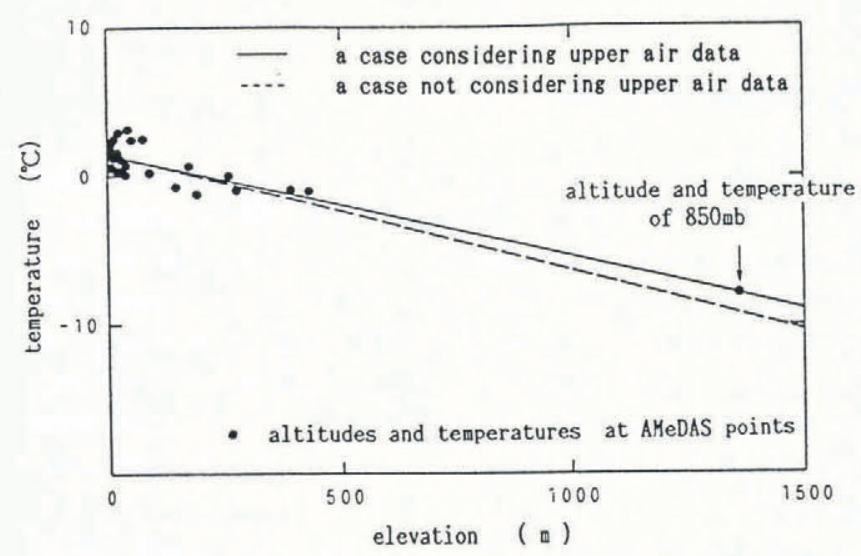

Fig. 4. Temperature lapse rate of elevation.

After that, we transformed temperatures at AMeDAS points to temperatures at sea level by making use of the temperature lapse rate. We calculated the temperature in each mesh through a distance-weighted interpolation method, and retransformed these values to temperatures at the elevation of each mesh.

In calculating the interpolating equation for predicting temperature change, we improved the accuracy of prediction by using values which were measured before prediction. The pattern of temperature change in a day depends on the minimum temperature in the morning or 


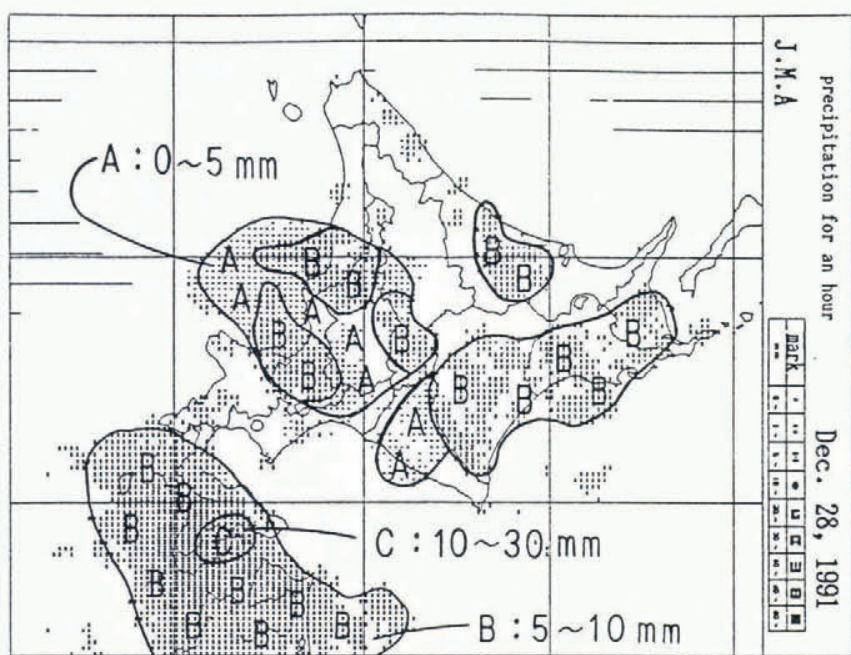

Fig. 5. Radar-AMeDAS Composite Chart.

the maximum in the daytime. So, we can obtain more accurate values if we begin the prediction after getting real values.

Although we had upper air data twice a day $(0900$ and $2100 \mathrm{~h}$ ), we used the latest values at Sapporo in beginning the prediction.

\section{Technique of predicting precipitation}

In the nowcast technique we made use of the precipitation nowcast announced by the JMA. First, they make the distribution of precipitation for every hour on a Radar-AMeDAS Composite Chart as the initial value (Fig. 5). This is the $5 \mathrm{~km} \times 5 \mathrm{~km}$ mesh distribution of precipitation intensity calculated by values measured with an AMeDAS rain gauge on the ground. Then they forecast precipitation distribution for $3 \mathrm{~h}$ ahead by calculating the initial value through a kinematic technique. Additionally, through a numerical model
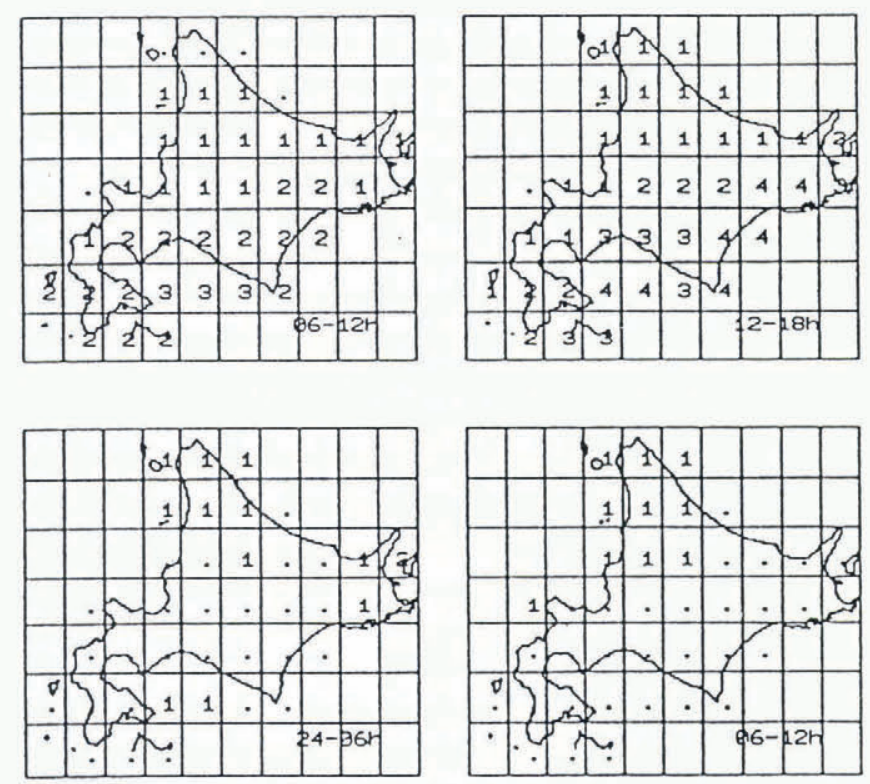

Fig. 6. MRR (mean rainfall rate) for 3 April 1990: , $0-1 \mathrm{~mm} ; 1,1-3 \mathrm{~mm} ; 2,3-5 \mathrm{~mm} ; 3,5-7 \mathrm{~mm}$; and 4, 7-9 $\mathrm{mm}$ of precipitation. and echo data, they predict whether precipitation in a sector will increase or decrease with a calculated result of atmospheric conditions.

Using this precipitation nowcast, we obtained the forecasted precipitation data of a $5 \mathrm{~km} \times 5 \mathrm{~km}$ mesh $3 \mathrm{~h}$ in advance, every hour on the hour.

In the short-range forecast we predicted precipitation at each AMeDAS point by using mean rainfall rate (MRR) which is part of the Guidance in Connection with Precipitation to Weather Forecast announced twice a day by the JMA. MRR, the forecasted mean rainfall rate for every $6 \mathrm{~h}$ divided into nine ranks, is sent every $6 \mathrm{~h}$, $9-45 \mathrm{~h}$ in advance. Guidance data is divided with cross stripes as in Figure 6.

Figure 7 shows the prediction technique using MRR. We first calculated the correlation between $6 \mathrm{~h}$ measured precipitation in each mesh and $6 \mathrm{~h}$ measured precipita-

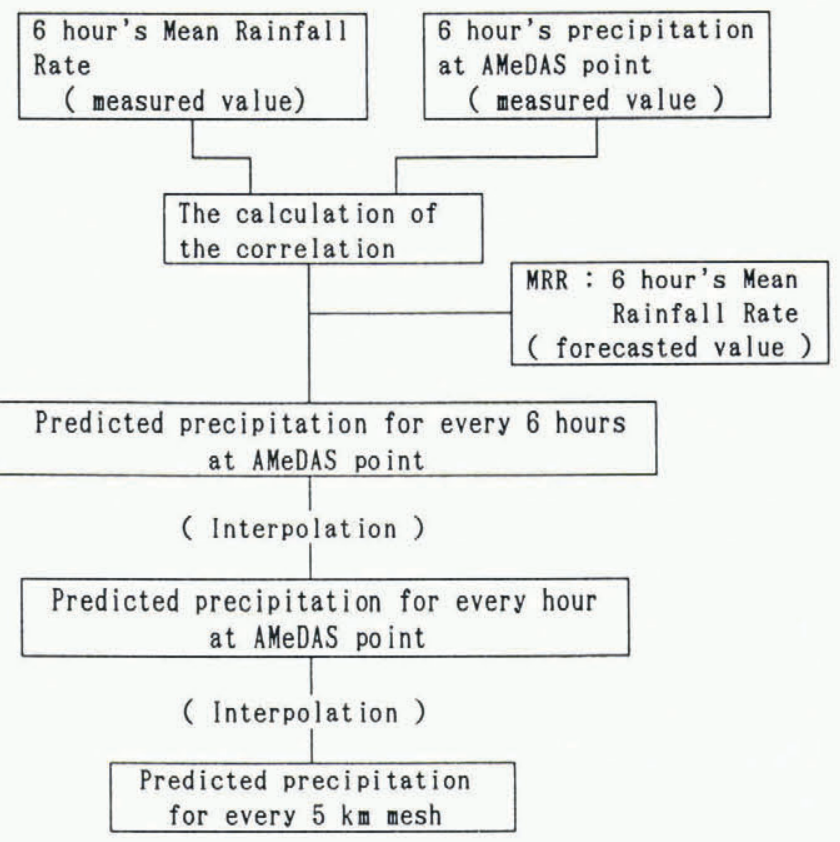

Fig. 7. Flow chart showing short-range forecast of precipitation.

tion at the AMeDAS point in each mesh. In accordance with this relational formula, we calculated predicted precipitation for every $6 \mathrm{~h}$ at each AMeDAS point from MRR. Then, using these figures we interpolated predicted precipitation for every hour at each AMeDAS point through a Spline function. We calculated precipitation for every $5 \mathrm{~km} \times 5 \mathrm{~km}$ mesh by the distanceweighted interpolation method. As a result we can predict precipitation for every hour, $24 \mathrm{~h}$ in advance.

\section{Technique of predicting wind direction and speed}

We used a one-level, mesoscale model (Mass and Dempsey, 1985) for diagnosing surface winds so that we could obtain an accurate computation of the real wind distribution. Various elements were used as parameters in the model: (1) geostrophic wind; (2) friction between sea and land; (3) decrease of wind speed through ground friction; (4) shift of wind direction between geostrophic 
wind and surface wind; (5) temperature difference between sea and land; (6) heating and cooling on the ground; (7) distribution of downward motion by landand sea-breeze circulation or radiation cooling; and (8) upper stratification condition (atmospheric stability).

In order to predict geostrophic wind, we read forecasting values of atmospheric pressure at four points, Sapporo, Aomori, Urakawa and Suttu, $36 \mathrm{~h}$ in advance, every $12 \mathrm{~h}$ from the JMA numerical weather prediction chart. Using these values, we interpolated atmospheric pressure for every hour at each point through a Spline function so that we could obtain every hour the predicted geostrophic wind by atmospheric pressure field on four points.

For upper air data (height of $1000 \mathrm{mb}, 850 \mathrm{mb}$ and $700 \mathrm{mb}$, temperature of $850 \mathrm{mb}$ and $700 \mathrm{mb}$ ) we used the newest value in observed values announced at 0900 and $2100 \mathrm{~h}$ by the JMA.

We calculated the difference in temperature between the sea and land by using mean sea and land temperatures in February for the southern part of Hokkaido.

For topographical data we used mean values of elevation in each mesh from the Geographical Survey Institute's Collection of Digital Geographic Information.

If we calculate wind direction and speed by using these parameters on the three-dimensional topography, the atmosphere is forcibly made to go up and down. As above, adiabatic process occurs, so that the wind flow is controlled and we can obtain the distribution of new wind.

We have presented here our use of a one-level, mesoscale model for diagnosing surface winds, but we also researched the prediction of wind direction and speed using a potential-flow model (Nagasawa and others, 1984 .

\section{The calculation of predicted substantial precipita- tion}

The prediction of substantial precipitation was calculated by the predicted value of temperature, precipitation and wind in each mesh calculated by these predicting techniques. We formed this parameter as an important index to the snow accretion forecast through weather analysis of past snow accretion cases. The prediction of substantial precipitation is defined by

$$
\begin{aligned}
I_{\mathrm{n}} & =k \cdot I_{\mathrm{g}} \\
\text { and } \quad k & =v / u,
\end{aligned}
$$

where $I_{\mathrm{n}}$ is substantial precipitation, $v$ is wind speed, $u$ is snow falling speed, and $I_{g}$ is precipitation on the ground. Generally the falling speed of a snow flake, which is snow at a suitable temperature for snow accretion, is about $1 \mathrm{~m} \mathrm{sec}^{-1}$.

Figure 8 shows the calculation method for predicting substantial precipitation by weather elements. There was a difference among areas. We calculated $I_{\mathrm{n}}$ by using Equations (1) and (2) for a fall speed of $1 \mathrm{~m} \mathrm{sec}^{-1}$, assuming a suitable temperature $\left(0^{\circ} \sim+2^{\circ} \mathrm{C}\right)$ for snow accretion. At other temperatures $I_{\mathrm{n}}$ would be 0 .

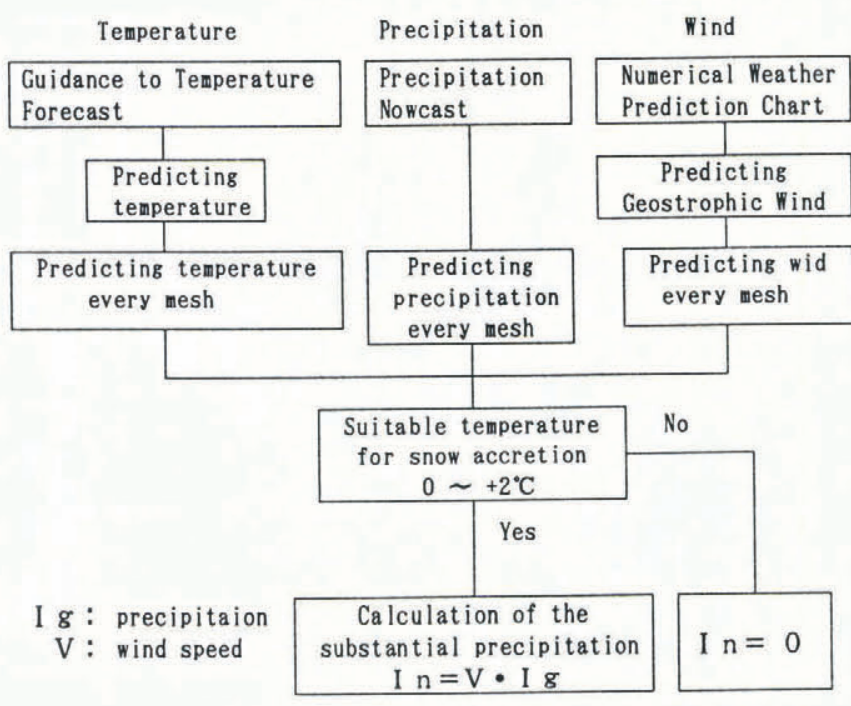

\section{Fig. 8. Calculation method of predicting substantial} precipitation.

\section{Examples of predicted result}

By applying the above method to many examples of wet snow accretion, we were able to check the prediction of weather elements. The following were some of many examples of predicted results of temperature, precipitation, wind and substantial precipitation over three hours from $0900 \mathrm{~h}$ on 28 December 1991. On that day they gave an advisory on snow accretion, heavy snow, snowstorms, warnings for snowstorm and heavy snow. Snow accretion occurred on the transmission lines. Figure $9 \mathrm{a}-\mathrm{d}$ represents the measured and the predicted values.

The predicted temperature value is a little higher $\left(+2^{\circ} \mathrm{C}\right)$ than the measured value (Fig. 9a).

Figure $9 \mathrm{~b}$ shows precipitation. There is a little difference in the spread of rainfall over the area, but the predicted value is mostly close to the measured value.

Figure 9c shows the measured and the predicted values of wind. As the measured value is interpolated from the values of the AMeDAS points, it is the equalized distribution; high wind is rather difficult to calculate in principle. Another reason is that most AMeDAS points are located in low-wind areas and the values are not rectified for each elevation. It is not shown in the figures, but the measured values on some transmission lines are rather closer to the predicted values than the values calculated as the mean values for the meshes.

Figure $9 \mathrm{~d}$ shows values of substantial precipitation. As the values of predicted substantial precipitation are calculated from weather elements, they have the predicted errors of the elements.

The distribution of substantial precipitation is calculated by discrimination of the suitable temperature for snow accretion. Also, it is calculated by discrimination between precipitation and no precipitation as substantial precipitation is the product of precipitation and wind speed. Consequently the mesh distribution of the substantial precipitation in fields is not always close to the distribution of the predicted value. 

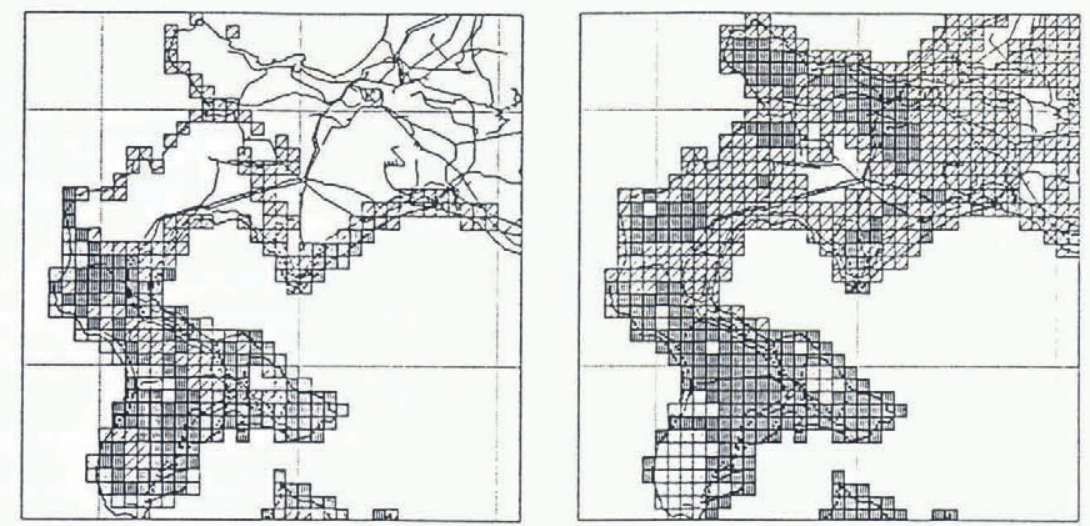

rank

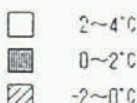

a
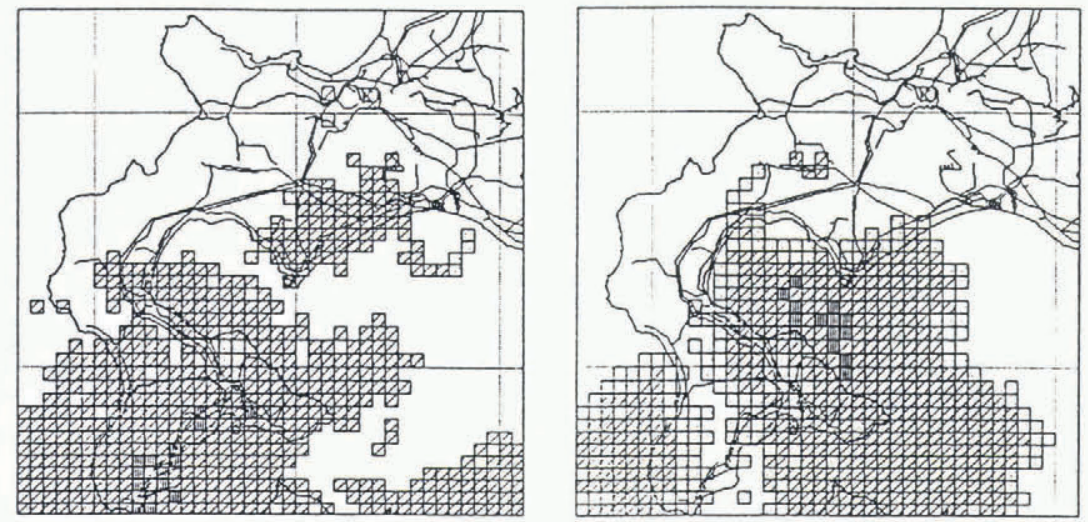

rank

$\square$ under lam

ए1-4m

回 $5-9$ min

圈 $10-19 \mathrm{~mm}$

붐 $20-29 \mathrm{~mm}$ b
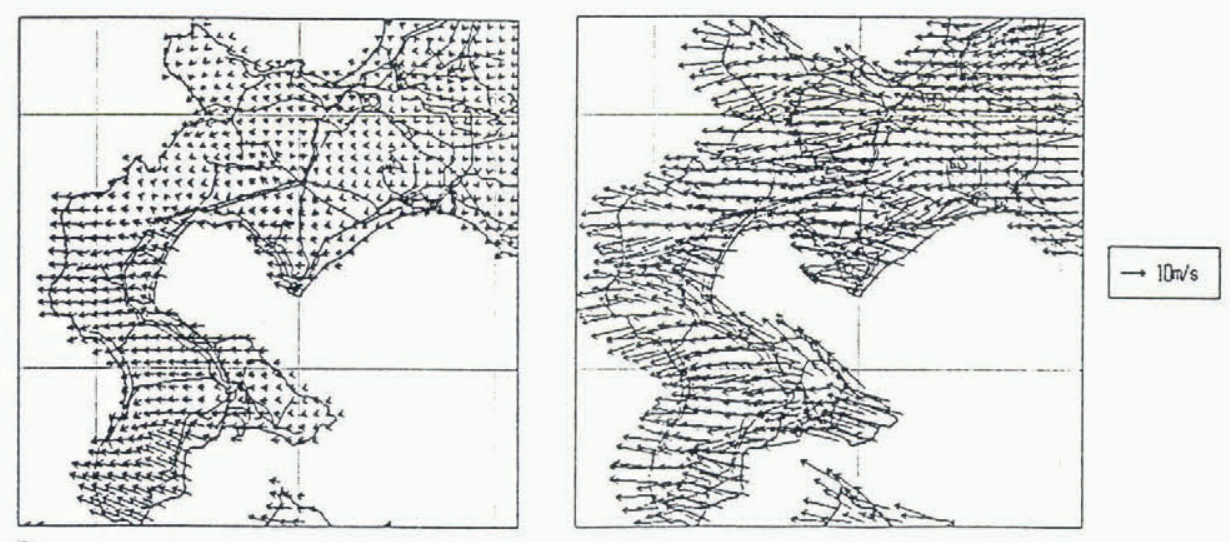

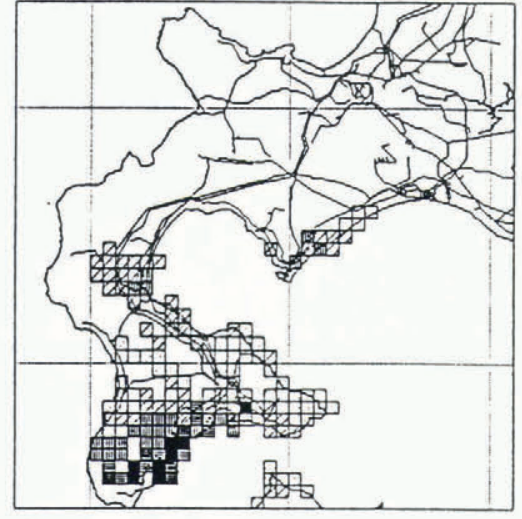

d

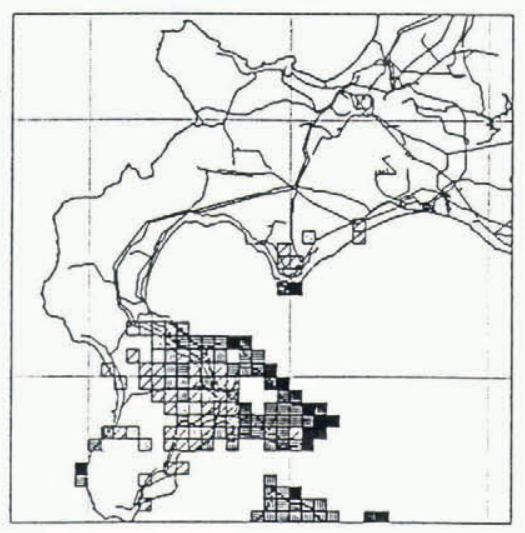

rank

(1- $4 m$

Z5-9rm

圆 10-19m

瞍 20-29:m

圈 $30-39$ m

over 40m

predicted value

Fig. 9. Measured values for $1100 \mathrm{~h}$ on 28 December 1991 and predicted values for $0900 \mathrm{~h}$ on the same day. a, temperature; $b$, precipitation (measured from Radar-AMeDAS composite chart); c, wind; d, substantial precipitation. 


\section{CONGLUSIONS}

A meteorological forecasting method is a necessary part of the snow accretion forecasting system, and the accuracy of the meteorological forecast directly affects that of the system. Therefore we must study more past snow accretion occurrences and predicted results, and then improve the method to increase accuracy.

We plan to classify the snow accretion by a risk scale with meteorological forecasting values and other elements, and hope, in the near future, to complete the system for practical use.

\section{REFERENGES}

Mass, C.F. and D. P. Dempsey. 1985. A one-level, mesoscale model for diagnosing surface winds in mountainous and coastal regions. Mon. Weather Rev., 113(7), 1211-1227.

Nagasawa, S., S. Okamoto, S. Umeda, Y. Ooishi, A. Ootaki and K. Shiozawa. 1984. Studies on prediction in complex terrain (I). Wind field model. $\mathcal{F}$. Jpn Soc. Air Pollut., 19(2), 149-158.

The accuracy of references in the text and in this list is the responsibility of the authors, to whom queries should be addressed. 